ARTICLE

Received 11 Apr 2014 | Accepted 17 Jun 2014 | Published 22 Jul 2014

DOI: $10.1038 /$ ncomms5412 OPEN

\title{
Light and pheromone-sensing neurons regulates cold habituation through insulin signalling in Caenorhabditis elegans
}

Akane Ohta $^{1, \star}$, Tomoyo Ujisawa ${ }^{1, \star}$, Satoru Sonoda ${ }^{1} \&$ Atsushi Kuhara ${ }^{1}$

Temperature is a critical environmental stimulus that has a strong impact on an organism's biochemistry. Animals can respond to changes in ambient temperature through behaviour or altered physiology. However, how animals habituate to temperature is poorly understood. The nematode $C$. elegans stores temperature experiences and can induce temperature habituation-linked cold tolerance. Here we show that light and pheromone-sensing neurons (ASJ) regulate cold habituation through insulin signalling. Calcium imaging reveals that ASJ neurons respond to temperature. Cold habituation is abnormal in a mutant with impaired cGMP signalling in ASJ neurons. Insulin released from ASJ neurons is received by the intestine and neurons regulating gene expression for cold habituation. Thus, temperature sensation in a light and pheromone-sensing neuron produces a robust effect on insulin signalling that controls experience-dependent temperature habituation.

\footnotetext{
${ }^{1}$ Laboratory of Molecular and Cellular Regulation, Faculty of Science and Engineering, Institute for Integrative Neurobiology, Konan University, 8-9-1 Okamoto, Higashinada-ku, Kobe 658-8501, Japan. * These authors contributed equally to this work. Correspondence and requests for materials should be addressed to A.O. (email: aohta@center.konan-u.ac.jp) or to A.K. (email: kuhara@center.konan-u.ac.jp).
} 
$\mathrm{T}$ emperature is one of the most critical environmental stimuli and causes biochemical changes in the body. Animals including humans can, therefore, respond and habituate to changes in ambient temperature. The nematode Caenorhabditis elegans is a useful model for studying the mechanism of temperature habituation, because of its powerful molecular genetics. Previous study by Murray et al. ${ }^{1}$ demonstrated that $C$. elegans has a cold tolerance that is regulated by phospholipid saturation. Savory et al..$^{2}$ previously reported that cold tolerance is regulated by molecules involved in the ageing pathway, such as FOXO-type transcription factors and PI3 kinase. The essential organs and tissues for systematic regulation of cold tolerance in C. elegans, however, remain unknown.

In this study, we investigated the molecular physiological mechanisms underlying temperature experience-dependent cold tolerance in C. elegans. Our $\mathrm{Ca}^{2+}$ imaging and genetic analyses reveal that light and pheromone-sensing (ASJ) neurons receive temperature input and transmit information through a photo signal-transduction pathway. Insulin released from ASJ neurons is received in the intestine and neurons, which controls cold habituation. Our study describes systematic regulation of cold habituation in a living animal.

\section{Results}

As previously reported by Murray et al. ${ }^{1}$ and Savory et al. ${ }^{2}$, C. elegans has a cultivation temperature-dependent cold tolerance. Wild-type animals cultivated at 20 or $25^{\circ} \mathrm{C}$ were killed by cold shock. In contrast, most wild-type animals cultivated at $15^{\circ} \mathrm{C}$ survived after cold shock (Fig. 1a). To examine the conditions of temperature experience-dependent cold tolerance in detail, we used varying cold-shock temperatures $\left(0-4{ }^{\circ} \mathrm{C}\right)$ (Fig. 1b), cultivation temperatures $\left(13-27^{\circ} \mathrm{C}\right)$ (Fig. 1c) and cold-shock times (6-240 h) (Supplementary Fig. 1a-c). Cold tolerance decreased when cultivation temperature was higher, when cold-shock temperature was lower and when cold-shock time was longer. We used $2^{\circ} \mathrm{C}$ for $48 \mathrm{~h}$ as a typical cold-shock treatment for the majority of the following experiments. To determine whether cold tolerance was established at a specific developmental stage, we performed temperature shift experiments using larvae between the L1 and L4 stages (Fig. 1d,e). We found that a shift of cultivation temperature at larval stages did not severely affect the cold tolerance of adult animals (Fig. 1d,e). To understand how long it takes for cold tolerance to be established in adult animals, we shifted the temperature of adult animals (Fig. 1f,g). Unexpectedly, cold tolerance was established only $2-3 \mathrm{~h}$ after the cultivation temperature was changed from 25 to $15^{\circ} \mathrm{C}$ (Fig. 1f) or from 20 to $15^{\circ} \mathrm{C}$ (Fig. $1 \mathrm{~g}$ ). Furthermore, cold tolerance was diminished $2-3 \mathrm{~h}$ after the cultivation temperature was changed from 15 to $25^{\circ} \mathrm{C}$ (Supplementary Fig. 1d) or 20 to $25^{\circ} \mathrm{C}$ (Supplementary Fig. 1e). Detailed-phenotypic analyses indicated that temperature experience for the formation of cold tolerance can be overwritten within $2-3 \mathrm{~h}$.

We next investigated which tissues were involved in temperature experience-dependent cold tolerance, by examining the phenotypes of various tissue-specific mutants. We found that a mutant with defective unc-104/kinesin in almost all neurons showed abnormal enhancement of cold tolerance after cultivation at $20^{\circ} \mathrm{C}$ (Fig. $\left.2 \mathrm{a}\right)^{3,4}$. By contrast, mutants with impairments in the cuticle or body wall muscle did not display cold tolerance abnormalities (Fig. 2a). These data suggest that temperature experience-dependent cold tolerance is regulated, at least in part, by neurons. A known-neural circuit for thermotaxis behaviour of C. elegans involves temperature sensing and processing 5,6 We next examined the cold tolerance of mutants defective in the development or function of the temperature-sensing neurons participating in the thermotaxis neural circuit, AFD and AWC, and their downstream interneurons AIY and RIA (Fig. 2b; Supplementary Fig. 2a) ${ }^{5-7}$. Developmental or functional defects of these component neurons of the thermotaxis circuit did not lead to abnormal cold tolerance (Fig. 2b), suggesting that this known temperature-processing neural circuit is not essential for temperature experience-dependent cold tolerance. We found that the thermotaxis mutant, tax-6, which lacks calcineurin function in many neurons, had abnormal cold tolerance (Fig. $2 b)^{8,9}$. This abnormality was partially rescued by the expression of the tax-6 gene in sensory neurons as well as in almost all neurons (Fig. $2 \mathrm{~b}$, tax-6;Ex[unc-14p:: tax-6] (almost all neurons), tax-6;Ex[tax$6 p(1.1 \mathrm{~kb})::$ tax -6$]$ (many sensory neurons (amphid and phasmid))). These results imply that sensory neurons are important for cold tolerance. We therefore measured temperature experience-dependent cold tolerance in mutants with defective sensory neurons (Fig. 2c; Supplementary Fig. 2b). Mutant animals with impaired che-13 and osm- 6 genes demonstrated severely abnormal cold tolerance after cultivation at $20^{\circ} \mathrm{C}$ (Fig. 2c). Both che-13 and osm-6 genes encode components of an intraflagellar transport complex that is essential for cilium function in the sensory ending of sensory neurons (Supplementary Fig. 2b) ${ }^{10-13}$, suggesting that sensory input may be essential for cold tolerance.

To identify essential sensory neurons for temperature experience-dependent cold tolerance (Fig. 2d; Supplementary Fig. 2b), we tested the cold tolerance of mutants defective in specific or multiple sensory neurons. A strong abnormality was observed in tax- 4 and tax-2 mutants lacking cGMP-gated channels that are expressed in several sensory neurons, such as AFD, AWC, ASJ and ASI (Fig. 2d; Supplementary Fig. 2b) ${ }^{14}$. We therefore expressed tax-4 complementary DNA (cDNA) in ASJ, AWC and/or ASI sensory neurons of tax-4 mutants using cell-specific promoters (Fig. 2e, tax-4;Ex[trx-1p::tax-4] (ASJ), tax-4;Ex[str3p::tax-4] (ASI) and tax-4;Ex[ceh-36p::tax-4] (AWC)). We found that the abnormality of $\operatorname{tax}-4$ mutants was rescued by the specific expression of tax-4 $c D N A$ in a single pair of sensory neurons, ASJ neurons, which are known as light and pheromone-sensing neurons (Fig. 2e) ${ }^{15}$. In addition, laser ablation of ASJ sensory neurons in wild-type animals induced abnormal cold tolerance, which was similar to the tax-4 mutant phenotype (Fig. 2f). These results suggest that cultivation temperature-dependent cold tolerance is controlled by ASJ sensory neurons, and that ASJ neurons negatively regulate cold tolerance.

We hypothesized that ASJ neurons act as thermosensory neurons. To examine this hypothesis, we used the genetically encoded calcium indicator, cameleon ${ }^{16,17}$, to perform calcium imaging of the ASJ neuron under temperature changes. The cameleon gene, $y c 3.60$, was expressed in ASJ sensory neurons under the $t r x-1$ promoter. We found that the calcium concentration in ASJ neurons changes in response to temperature (Fig. 3a,b; Supplementary Fig. 2c,d). By contrast, this temperature response was decreased in the tax-4 mutant, which lacks a cGMP-gated channel essential for sensory signalling in ASJ (Fig. 3c,d). The defect in tax-4 mutants was rescued by specific expression of tax-4 cDNA in ASJ neurons, even in the absence of expression in the sensory neurons that regulate thermotaxis, such as AFD, AWC and ASI (Fig. 3c,d). Thus, physiological and genetic analyses suggest that ASJ acts as a temperature-sensing neuron. Moreover, the temperature response of ASJ was normal in the mutant with impaired SNB-1/ synaptobrevin (Fig. 3f), suggesting that ASJ responses to temperature changes are cell autonomous and do not require neurochemical input from other neurons. 
a

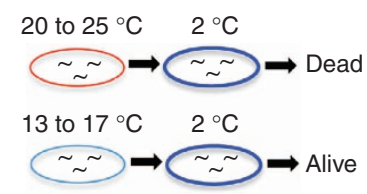

b

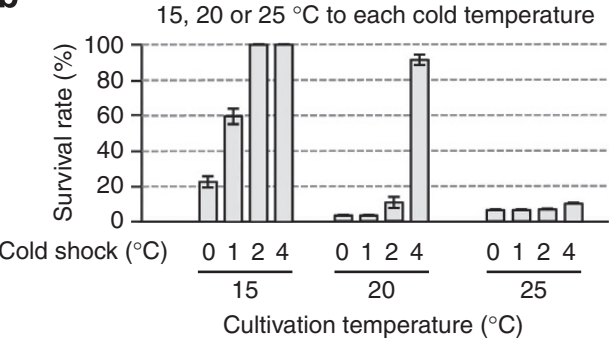

c

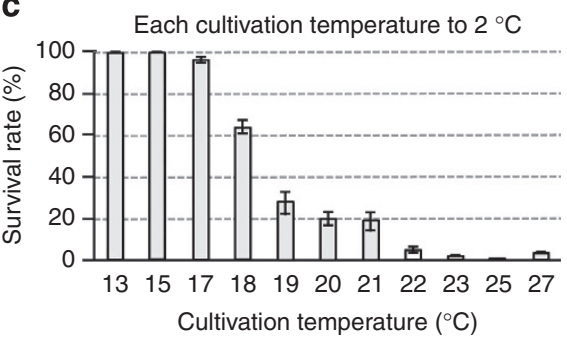

d
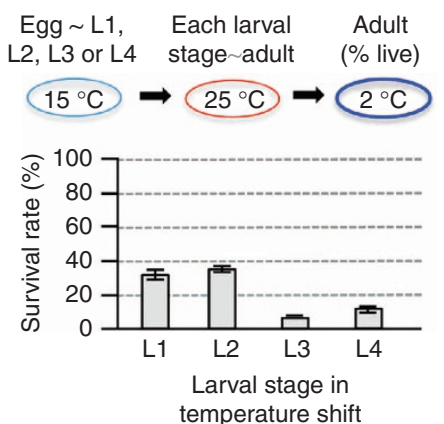

$\mathbf{f}$

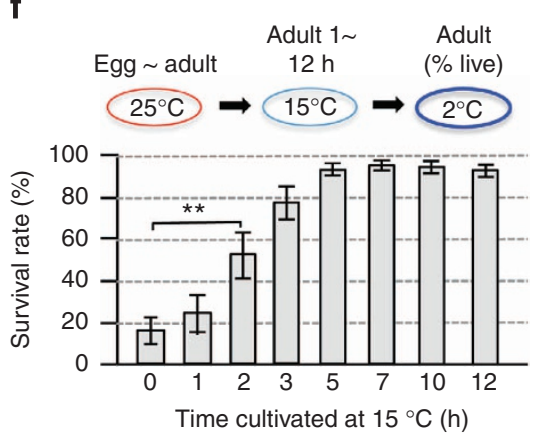

e

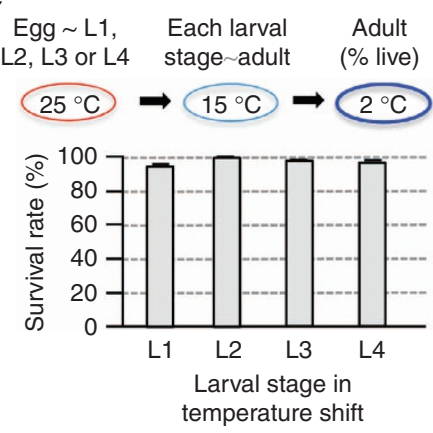

g

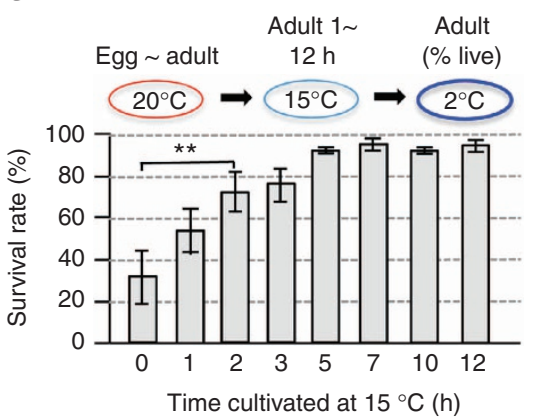

Figure 1 | Temperature experience-inducing cold tolerance phenotype in wild type. N2 (Bristol) strain was used as the wild-type animal in all experiments for this figure. (a) Cultivation temperature-dependent cold tolerance. Twenty to twenty-five degree centigrade-cultivated animals cannot live after cultivation at $2^{\circ} \mathrm{C}$ for $48 \mathrm{~h}$, while $13-17^{\circ} \mathrm{C}$-cultivated animals can live after $48 \mathrm{~h}$ at $2^{\circ} \mathrm{C}$. (b) Effect of cold-shock temperatures $\left(0,1,2\right.$ and $4^{\circ} \mathrm{C}$ ). Fifteen degree centigrade-cultivated animals can survive at 2 and $4^{\circ} \mathrm{C}$. Twenty degree centigrade-cultivated animals can survive at $4^{\circ} \mathrm{C}$. Twenty-five degree centigrade-cultivated animals cannot survive at $0-4^{\circ} \mathrm{C}$. For each assay, $n \geq 6$. (c) Effect of cultivation temperatures (from $13-27^{\circ} \mathrm{C}$ ). Thirteen to fifteen degree centigrade-cultivated animals can survive at $2{ }^{\circ} \mathrm{C}$, while $20-27^{\circ} \mathrm{C}$-cultivated animals cannot survive at $2^{\circ} \mathrm{C}$. For each assay, $n \geq 6$. (d,e) Temperature shift experiments using L1 to L4 stage larvae $\left(15-25^{\circ} \mathrm{C}(\mathbf{d})\right.$ or $\left.25-15^{\circ} \mathrm{C}(\mathbf{e})\right)$. Worms are initially cultivated at the first temperature $\left(15^{\circ} \mathrm{C}(\mathbf{d})\right.$ or $\left.25^{\circ} \mathrm{C}(\mathbf{e})\right)$ from egg to each larval stage, and then worms were transferred to the second temperature $\left(25^{\circ} \mathrm{C}(\mathbf{d})\right.$ or $\left.15^{\circ} \mathrm{C}(\mathbf{e})\right)$ and cultivated until they reached adult stage. After the adult worms were subjected to cold shock $\left(2{ }^{\circ} \mathrm{C}, 48 \mathrm{~h}\right)$, survival rate was calculated. Cold tolerance is not dependent on the temperature experience at the larval stage. For each assay, $n \geq 6$. $(\mathbf{f}, \mathbf{g})$ Temperature shift experiments at the adult stage $\left(25-15^{\circ} \mathrm{C}(\mathbf{f})\right.$ or $\left.20-15^{\circ} \mathrm{C}(\mathbf{g})\right)$. Worms were cultivated at the first temperature $\left(25^{\circ} \mathrm{C}(\mathbf{f})\right.$ or $\left.20^{\circ} \mathrm{C}(\mathbf{g})\right)$ until they reached the adult stage, and then worms were transferred to the second temperature $\left(15^{\circ} \mathrm{C}(\mathbf{f}, \mathbf{g})\right)$ and cultivated for specific times $(0-12 \mathrm{~h}$ indicated on the horizontal axis). After the temperature shifted-adult worms were subjected to cold shock $\left(2^{\circ} \mathrm{C}, 48 \mathrm{~h}\right)$, survival rate was calculated. About $3 \mathrm{~h}$ after the cultivation temperature was changed, cold tolerance was acquired. For each assay, $n \geq 6$. Error bars indicate standard error of the mean. analysis of variance followed by Dunnet post-hoc test was used for multiple comparisons. ${ }^{\star \star} P<0.01$.

To analyze whether acclimation temperature alters ASJ neuron responsiveness to the temperature stimulus, we monitored calcium concentration changes in ASJ neurons of wild-type animals that were cultivated at 15,20 or $25^{\circ} \mathrm{C}$, by calcium imaging. Physiological analysis in this study suggested that the temperature response of ASJ neurons is altered by the cultivation 
a

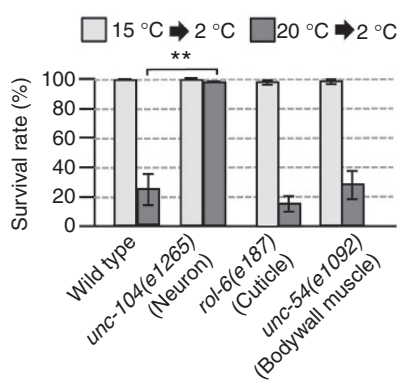

C

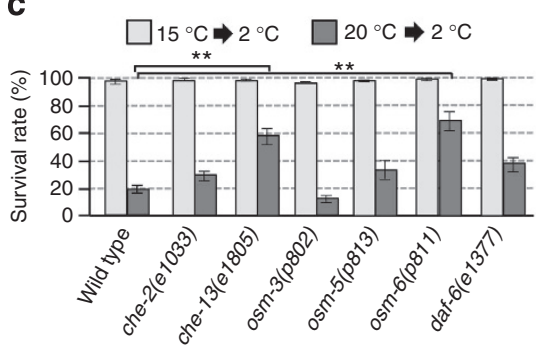

e

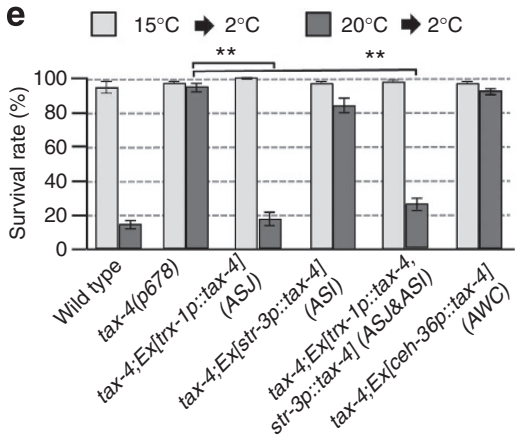

b

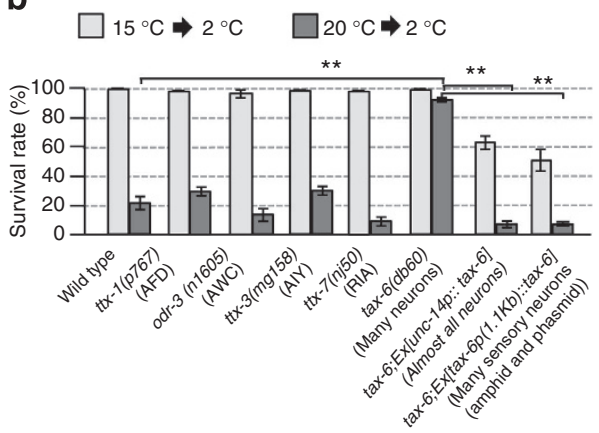

d

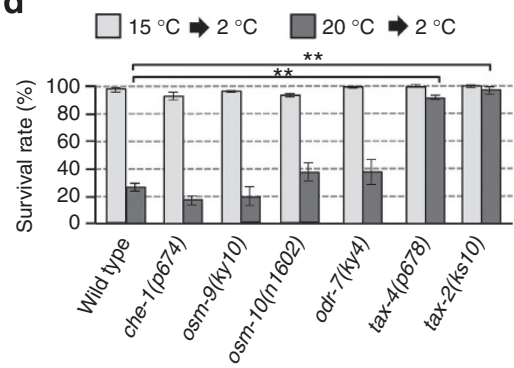

f

\begin{tabular}{ccccc}
\hline Treatment & $\begin{array}{c}\text { Number } \\
\text { of alive }\end{array}$ & $\begin{array}{c}\text { Number } \\
\text { of dead }\end{array}$ & Total & $\begin{array}{c}\text { Survival } \\
\text { rate(\%) }\end{array}$ \\
\hline ASJ killed & 11 & 4 & 15 & 73.3 \\
Mock & 1 & 20 & 21 & 4.76 \\
\hline
\end{tabular}

Figure 2 | ASJ sensory neurons are essential for cold tolerance. (a) Mutants impairing specific tissue functions. Mutant impairing unc-104/kinesin expression in neurons showed abnormal cold tolerance after cultivation at $20^{\circ} \mathrm{C}$, whereas mutants impairing rol-6/cuticle or unc-54/muscles did not show the defect. Strain names and alleles are indicated. For each assay, $n \geq 6$. (b) Mutants showing developmental or functional defects in thermotaxis neurons, AFD, AWC, AIY and RIA, did not demonstrate abnormal cold tolerance. tax-6 mutants showed abnormal cold tolerance, which was partially rescued by expressing the tax- 6 gene in all neurons (unc-14p::tax-6) or in sensory neurons $(\operatorname{tax}-6 p(1.1 \mathrm{~kb}):: \operatorname{tax}-6)^{8}$. The detailed information of these promoters is indicated in the Methods section. For each assay, $n \geq 6$. (c,d) Cold tolerance of mutants affecting sensory neurons. Gene products and cells expressing each gene are listed in Supplementary Fig. 2b. Both che-13 and osm-6 mutants showed abnormal increments of cold tolerance after $20^{\circ} \mathrm{C}$ cultivation (c). Twenty degree centigrade-cultivated tax-4 and tax-2 mutants, encoding the cGMP-gated channel, showed significant increments in cold tolerance (d). For each assay, $n \geq 6$. (e) Cell-specific expression of tax-4 cDNA in tax-4(p678) mutants. The promoters for cell-specific expression used in this experiment were the trx-1 promoter (ASJ), str-3 promoter (ASI) and ceh-36 promoter (AWC). Abnormal cold tolerance in tax-4(p678) was rescued by specific expression of tax4 cDNA in ASJ sensory neurons. For each assay, $n \geq 6$. (f) Laser-killing of ASJ sensory neurons affects normal cold tolerance. ASJ-ablated wild-type animals showed abnormal cold tolerance phenotypes after $20^{\circ} \mathrm{C}$ cultivation. The survival rate of ASJ-ablated animals was significantly increased from that of mocktreated wild-type animals. Error bars indicate standard error of the mean. analysis of variance followed by Dunnet post-hoc test was used for multiple comparisons. ${ }^{\star \star} P<0.01$.

temperature (Fig. 3b). We found that calcium concentration changes in ASJ neurons of 20 or $25-^{\circ} \mathrm{C}$-cultivated animals were stronger than those of $15-{ }^{\circ} \mathrm{C}$-cultivated animals. These results are consistent with the genetic results in this study that ASJ neurons negatively regulate cold tolerance, where reduced-ASJ activity enhances cold tolerance and increased-ASJ activity reduces cold tolerance.

To determine what molecules are involved in temperature signalling in ASJ neurons, we tested mutants defective in phototransduction in ASJ neurons ${ }^{15}$. We found that mutants of proteins involved in phototransduction in ASJ neurons, including trimeric G protein alpha subunits (gpa-1, gpa-3 or goa-1), guanylyl cyclase (daf-11; odr-1) or phosphodiesterase (pde-1; pde-2), showed abnormalities in cold tolerance (Fig. 4a,b). Although the specific neuron responsible for these abnormalities in cold tolerance was not determined, these results are consistent with a hypothesis that two sensory modalities, light and temperature, are transduced by shared signalling molecules. A lite-1 mutant, lacking a photoreceptor protein expressed in ASJ neurons, showed normal cold tolerance (Fig. 4a,b) and normal calcium concentration changes in ASJ neurons in response to temperature changes (Fig. 3c) ${ }^{15}$. Therefore, temperature is probably received in ASJ neurons by other receptors. 
a

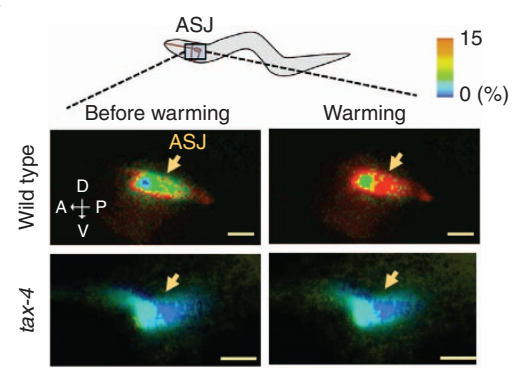

C

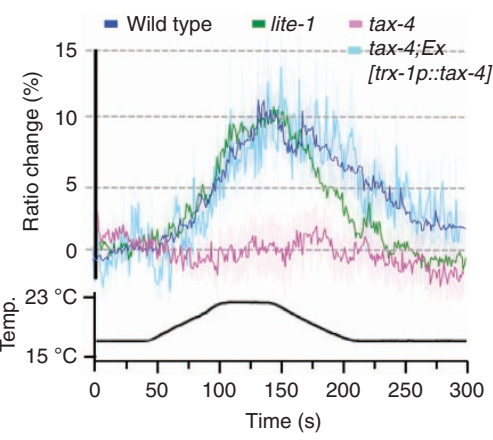

e

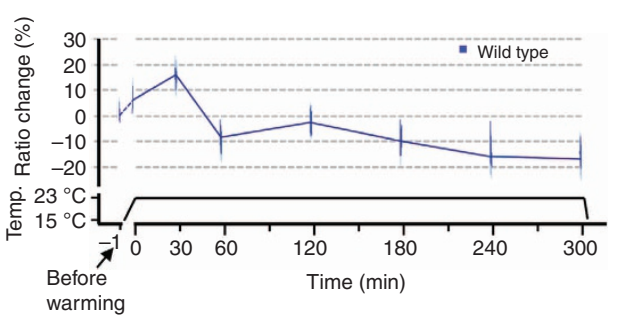

b

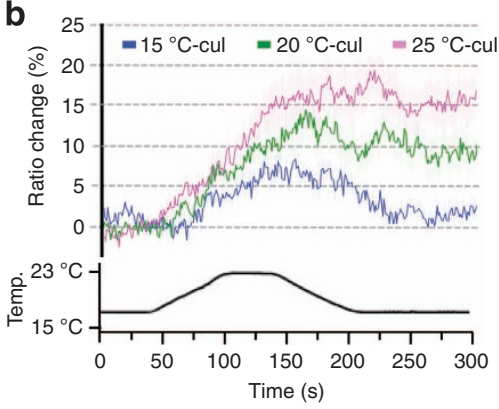

d

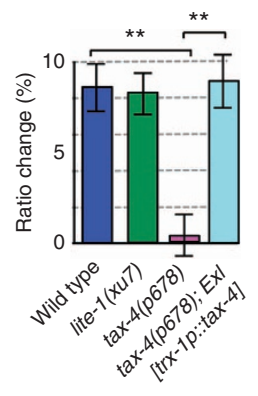

f

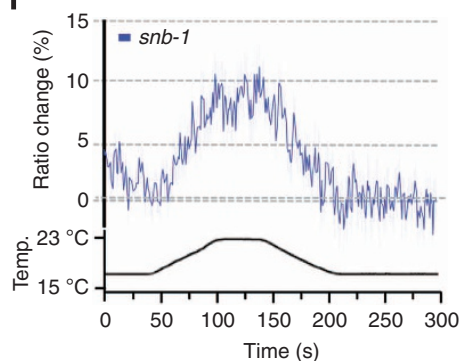

Figure 3 | Neural activity of ASJ sensory neuron with temperature stimuli. (a) Wild type and mutant expressing yellow cameleon driven by trx-1 promoter, trx-1p::yc3.60 (pTOM13), were tested by calcium imaging. Representative fluorescence resonance energy transfer signal in ASJ of wild type or tax-4 mutant cultivated at $15^{\circ} \mathrm{C}$ when worms were subjected to temperature changes. A schematic diagram of an ASJ in head, and corresponding pseudo colour images depicting fluorescence ratio of cameleon before and during temperature change. Arrows, indicate ASJ cell body. Scale bar, $10 \mu \mathrm{m}$. $(\mathbf{b}, \mathbf{c}, \mathbf{f})$ In vivo calcium imaging of ASJ from wild type cultivated at each temperature (b), mutants (c,f). Relative increase or decrease in the intracellular $\mathrm{Ca}^{2+}$ concentration was measured as an increase or decrease in yellow fluorescent protein/cyan fluorescent proteins fluorescence ratio of the cameleon (ratio change) during temperature changes. Temperature changes (ranging from $17-23^{\circ} \mathrm{C}$ ) with time are shown at the bottom of the graph. Calcium concentrations in ASJ of wild type change following temperature stimuli, which were observed in animals cultivated at different temperatures (b). Calcium concentration changes responding to temperature shifts were not observed in tax-4(p678) (c). lite-1 and tax-4; Ex[trx-1p::tax-4], which is a tax-4 mutant with specifically expressing tax-4 cDNA in ASJ, could respond to temperature changes (c). snb-1 (md247) mutants also responded (f). Each graph represents average response to temperature stimuli $(\mathbf{b}, \mathbf{c}, \mathbf{f}) . n=12-17$. (d) Bar graph showing average ratio change during $20 \mathrm{~s}$ from 120 to $140 \mathrm{~s}$ of the experiment indicated in (c). Colour key for bar graph is the same as that for the corresponding response curve in (c). (e) Calcium imaging of ASJ in wild type during longer times. At $30 \mathrm{~min}$ after temperature shift, intracellular $\mathrm{Ca}^{2+}$ concentration in ASJ was at its maximum, after which a decrease was observed and stabilized. Fluorescence ratio was measured at $-1,0,30,60,120,180,240$ and 300 min after temperature change. At each time point, fluorescence signal of cameleon was detected for $60 \mathrm{~s}$. Two Scale bars, -1 to $0 \mathrm{~min}$ and 0 to $300 \mathrm{~min}$, are shown on the horizontal line. The data were sequentially measured in chronological order using individual animals. $n=13$. Error bars indicate standard error of the mean. Analysis of variance followed by Dunnet post-hoc test was used for multiple comparisons. ${ }^{\star \star} P<0.01$.

We next investigated how ASJ sensory neurons control temperature experience-dependent cold tolerance. We demonstrated that mutants defective in synaptic transmission, including mutants of SNB-1/Synaptobrevin, SNT-1/Synaptotagmin, UNC64/Syntaxin or EGL-21/Neuropeptide processing enzyme, showed abnormal enhancement of cold tolerance phenotypes that were similar to those of ASJ-defective mutants (Fig. 5a). These results imply that neurotransmission is important for cold tolerance.

Previous reports suggest that cold tolerance is mediated by insulin-signalling pathways that are similar to pathways involved in dauer larva formation and ageing, and other stress tolerances, including oxidative stress $s^{18,19}$, ultraviolet light ${ }^{20}$, heavy metals ${ }^{21}$ and microbial infections ${ }^{22,23}$. However, specific insulin molecules and specific tissues involved in cold tolerance have not been determined. C. elegans has 40 genes encoding insulin-like molecules. We focused on two, DAF-28 and INS-6, which are expressed in ASJ sensory neurons ${ }^{24}$. We found that mutant animals defective in DAF-28 and INS-6 showed partial enhancement of cold tolerance (Fig. 5b,c; Supplementary Fig. 4c). Expressing daf-28cDNA in ASJ neurons of daf-28 


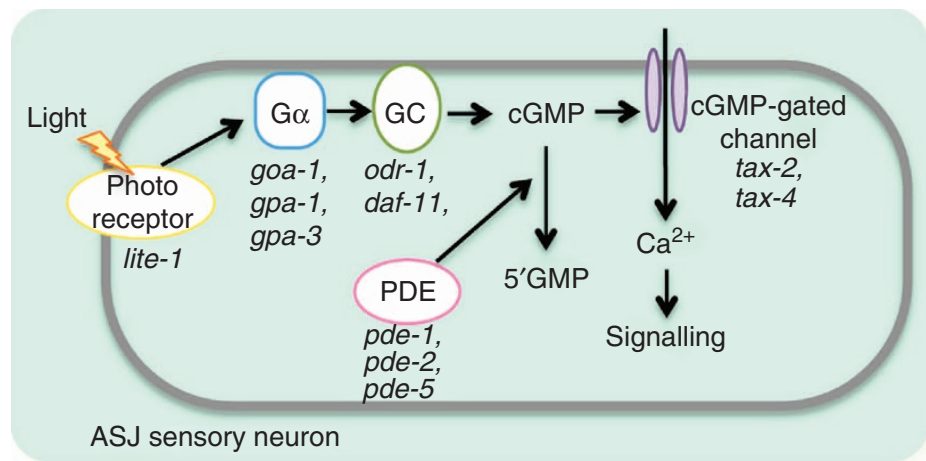

b

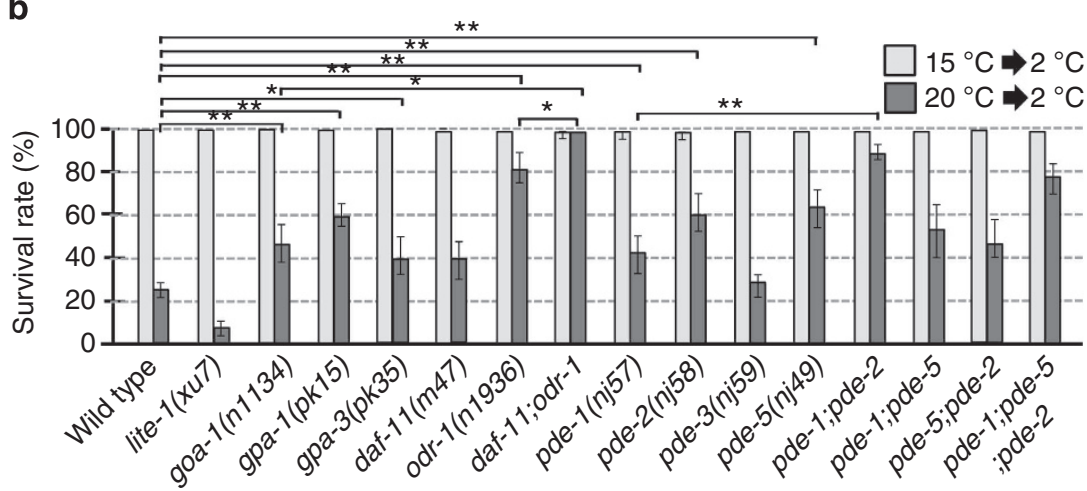

Figure 4 | Temperature information is processed through the cGMP pathway in ASJ neurons. (a) A molecular model of phototransduction in ASJ neurons, which is mediated by trimeric G-proteins and cGMP-dependent signalling ${ }^{15}$. (b) Cold tolerance of mutants with an impaired light-sensing pathway in ASJ neurons, which contains photoreceptor (lite-1), trimeric G protein alpha subunits (goa-1, gpa-1 and gpa-3), guanylyl cyclase (daf-11 and odr-1) and phosphodiesterase ( $p d e-1$ to 5). Allele names of double or triple mutants are the same for each single mutant. For each assay, $n \geq 6$. Error bars indicate standard error of the mean. Analysis of variance followed by Dunnet post-hoc test was used for multiple comparisons. ${ }^{\star} P<0.05$; ${ }^{\star \star} P<0.01$. Abbreviations: cGMP, cyclic guanosine monophosphate; $\mathrm{G} \alpha$, trimeric $\mathrm{G}$ protein alpha subunit; GC, guanylyl cyclase; PDE, phosphodiesterase.

mutants rescued abnormal cold tolerance, while expressing daf$28 c D N A$ in AWC neurons reduced the abnormality but tolerance did not return to wild-type levels (Fig. 5d). Previous reports demonstrated that AWC neurons probably act as a temperaturesensing neuron, and that the endogenous daf- 28 gene is not expressed in AWC sensory neurons from wild-type animals ${ }^{6,25}$. Based on these data, DAF-28 could be released from AWC by temperature stimuli in wild-type animals ectopically expressing daf-28 in AWC. Because the endogenous daf-28 gene is not expressed in wild-type AWC sensory neurons, these results suggest that DAF-28/insulin acts in a non-cell autonomous way, and is partially dependent on the neuron type. Similarly, a noncell autonomous phenomenon is observed in the secretorysignalling pathways of sensory neurons in C. elegans, such as insulin/INS-1-dependent temperature learning behaviour and neuropeptide-dependent neural discrimination ${ }^{26,27}$. In both cases, ectopic expression of secretory genes in sensory neurons of mutants partially rescued the abnormal phenotype of mutants.

Localization analysis using fluorescent proteins indicated that DAF-28 was co-localized with SNB-1/synaptobrevin at the synaptic region in ASJ neurons (Fig. 5e). By contrast, abnormal localization of DAF-28 in the cell body was observed in ASJ neurons of mutants with impaired UNC-104/kinesin, which is essential for cold tolerance (Supplementary Fig. 4d). These results imply that DAF-28/insulin is released from the synaptic region, and that DAF-28 is transported by kinesin into the synapse.

To determine the molecules downstream of insulin in temperature experience-dependent cold tolerance, we tested various mutants defective in the known insulin-signalling pathway (Figs 5b,c and 6a). Phenotypic analysis showed that mutants defective in the DAF-2/insulin receptor or its downstream molecules showed abnormal enhancement of cold tolerance (Figs 5c and 6a; Supplementary Fig. 4c) ${ }^{28}$. These results are consistent with a previous report showing that AGE-1/ PI3 kinase and DAF-16/FOXO are involved in cold tolerance ${ }^{2}$. DAF-2 is the only insulin receptor in C. elegans, while there are about 40 ligands for insulin receptors. Genetic epistasis analysis revealed that two insulins, DAF- 28 and INS-6, are both positive agonists that work redundantly on the DAF-2/insulin receptor in cold tolerance, because an ins-6; daf-28 double mutant showed a stronger phenotype than each single mutant (Fig. 5c) ${ }^{25,29}$. Additional genetic epistasis analysis indicated that INS-1/insulin genetically inhibits the DAF-2/insulin receptor through a negative regulation of INS-6/insulin (Fig. 5c, Supplementary Fig. 4c) ${ }^{26,30}$. Abnormal increments of cold tolerance in daf-2 mutants were suppressed by mutation in the DAF-16/FOXO-type transcriptional factor (Fig. 5c). We found that daf-16 mutant animals showed reduced cold tolerance after cultivation at $18^{\circ} \mathrm{C}$ (Supplementary Fig. 4b), although daf-16 mutant animals did not show decreased cold tolerance after cultivation at 20 or $15^{\circ} \mathrm{C}$ (Fig. 5c; Supplementary Fig. 4a). In contrast, overexpression of the daf-16 gene induced abnormal increments of cold tolerance (Fig. 5c (wild type; Is[daf-16])). These results suggest that DAF-2/ insulin receptor signalling and DAF-16/FOXO act as negative and positive regulators for cold tolerance, respectively. Because $15^{\circ} \mathrm{C}$ cultivated mutant animals defective in insulin signalling appeared to be cold tolerant (Supplementary Fig. 4a), it is probable that additional signalling pathways exist that lead to cold tolerance. 
a

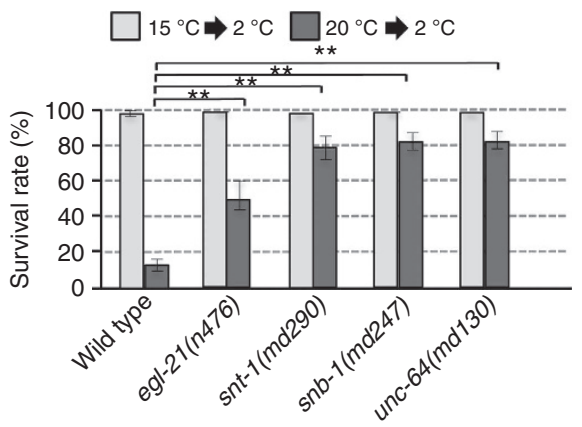

b

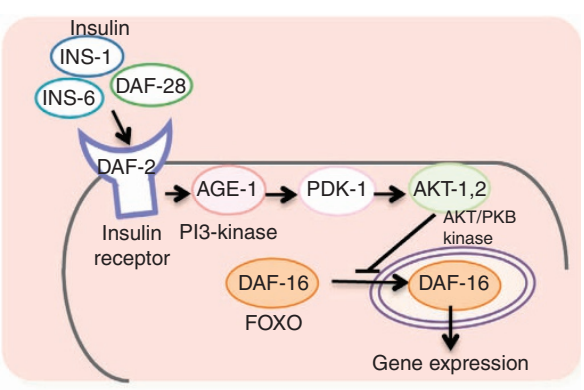

C

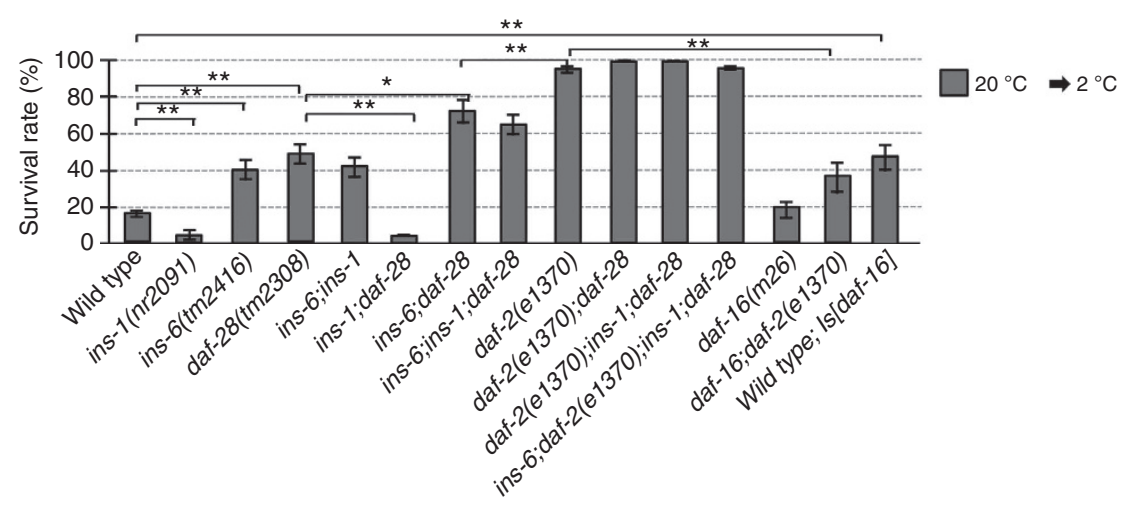

d

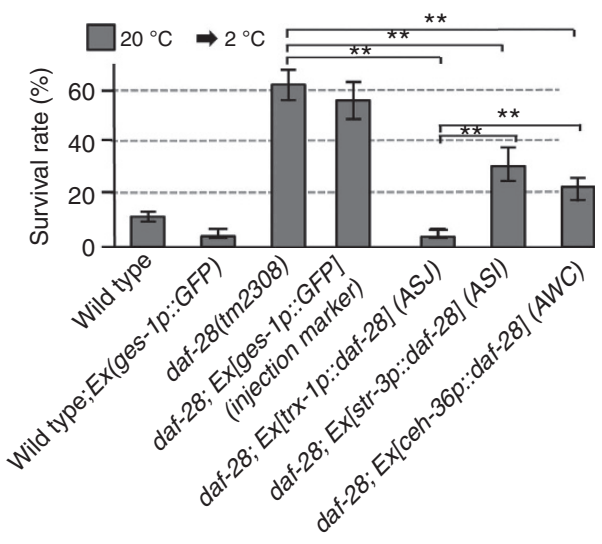

e
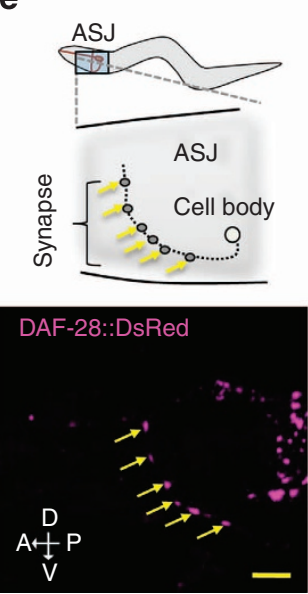
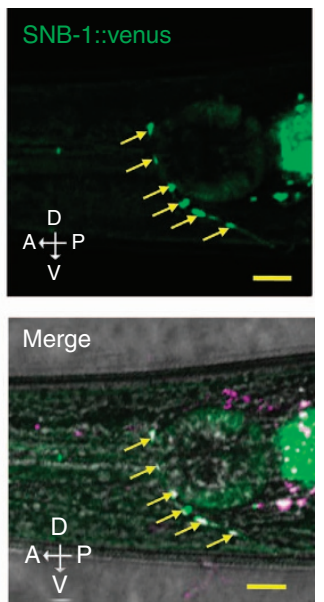

Figure 5 | Insulin signalling is involved in cold tolerance. (a) Cold tolerance of mutants with impaired synaptic transmission containing carboxypeptidase (egl-21), synaptotagmin (snt-1), synaptobrevin (snb-1) and syntaxin (unc-64). These mutants showed abnormal increments in cold tolerance. For each assay, $n \geq 6$. (b) A model of insulin signalling in dauer formation based on previous reports $23,24,27$. ins-1, ins- 6 and daf- 28 encode insulin. daf- 2 encodes the insulin receptor only in C. elegans. age-1 and pdk-1 encode phosphoinositide 3-kinase and 3-phosphoinositide dependent kinase, respectively. akt-1 and akt-2 encode serine/threonine kinase. daf-16 encodes FOXO transcription factor. Downstream cascade of DAF-2/insulin receptor contains AGE-1, PDK-1, AKT-1 and AKT-2. AKT-1 and AKT-2 inhibit nuclear translocation of DAF-16. Therefore, DAF-2 signalling negatively regulates DAF-16 in dauer formation. (c) Cold tolerance of mutants defective in insulin signalling. Animals of all strains were cultivated at $15^{\circ} \mathrm{C}$ from egg to L4 larvae, and after that, animals were cultivated at $20^{\circ} \mathrm{C}$ overnight from L4 to adult, because many insulin-signalling mutants showed constitutive dauer formation (daf-c) at $20^{\circ} \mathrm{C}$. Wild type; Is [daf-16] is an N2 strain with an integrated form of DAF-16::GFP, which also shows daf-c ${ }^{46}$. For each assay, $n \geq 9$. (d) Cell-specific rescue experiments of daf-28 null mutants. Cell-specific promoters used in this experiment were trx-1, str-3 or ceh-36 promoters for expression in ASJ, ASI or AWC cells, respectively. ges-1p::NLS-GFP was co-injected as a transgenic marker in all transgenic strains. For each assay, $n \geq 9$. (e) Localization of DAF-28 at the synapse of ASJ. Wild type with ASJ-specific expression of DAF-28::dsRedm and SNB-1::VENUS (wild type; Ex[trx-1p::daf-28:::dsRedm, trx-1p::snb-1::VENUS]) were analyzed by confocal microscopy. The upper-left panel indicates a schematic diagram of synapses in ASJ of head. In the upper-right panel, arrows indicate localization of synaptobrevin (SNB-1)::VENUS at synapses in ASJ. In the bottom-left panel, arrows indicate localization of DAF-28::dsRedm in ASJ. The bottom-right panel is the merged image of upper-right panel, bottom-left panel and bright-field image. In the merged image, arrows indicate white regions that suggest co-localization of SNB-1::VENUS and DAF-28::DsRedm at synapses. Scale bar, $10 \mu \mathrm{m}$. Error bars indicate standard error of the mean. Analysis of variance followed by Dunnet post-hoc test was used for multiple comparisons. ${ }^{\star} P<0.05 ;{ }^{\star} P<0.01$.

As previously reported, mutations in the insulin pathway, including the daf-2 mutation, extend lifespan, which induce better tolerance under a variety of stress conditions. An ambient temperature of $2{ }^{\circ} \mathrm{C}$ is considered an extremely stressful environment for worms. We tested cold tolerance of the mutants, $h s f-1 /$ heat-shock factor, jnk-1/MAP kinase, $k g b-1$ and $k g b-2 / \mathrm{MAP}$ 


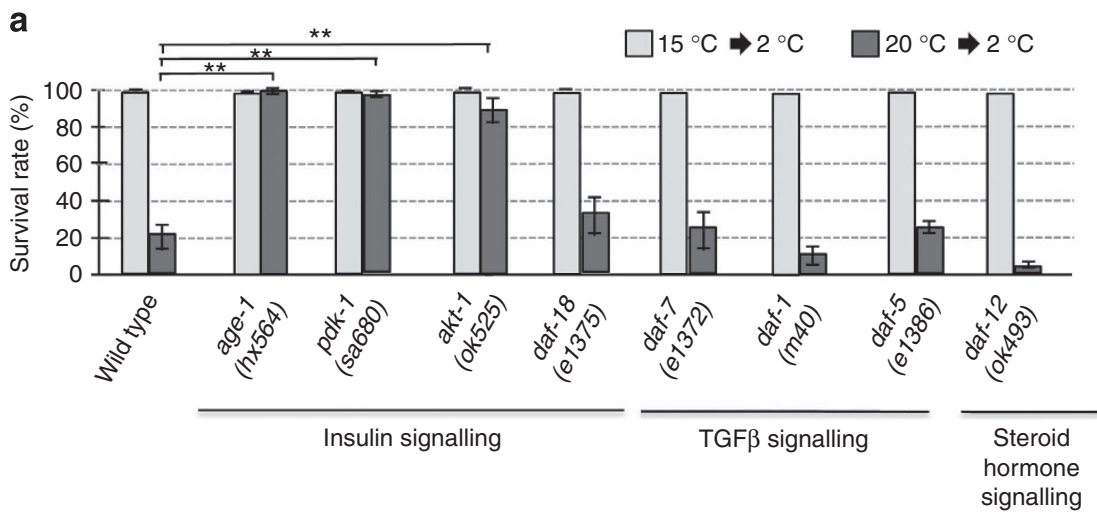

b

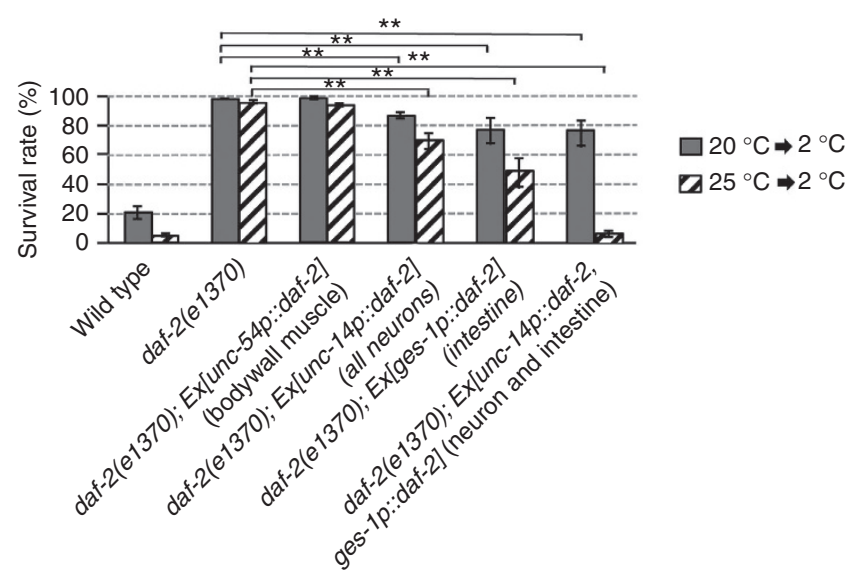

C

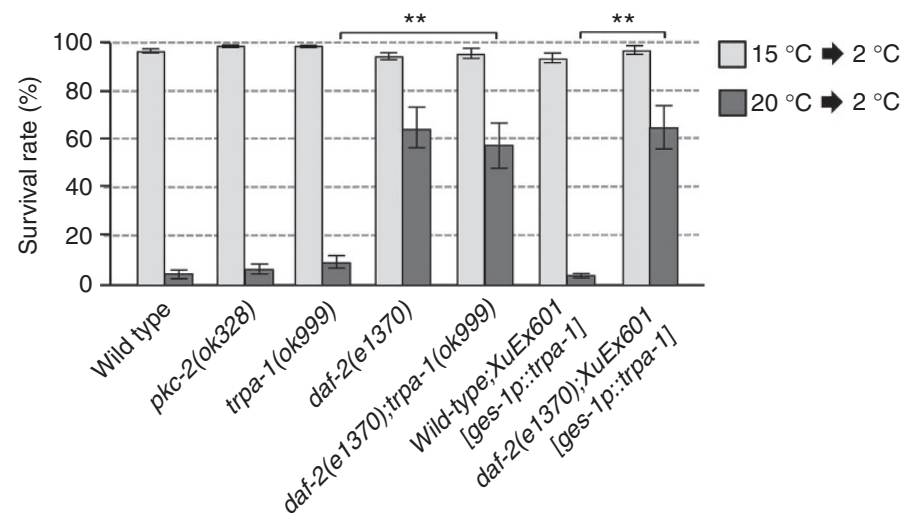

Figure 6 | Insulin signalling regulates gene expression during cold tolerance. (a) Temperature experience-dependent cold tolerance of mutants defective in insulin signalling, TGF- $\beta$ signalling or steroid hormone signalling. Mutants defective in insulin signalling showed abnormal cold tolerance after $20^{\circ} \mathrm{C}$ cultivation. In contrast, mutants of TGF- $\beta$ signalling and steroid hormone signalling showed normal cold tolerance. For each assay, $n \geq 6$. (b) Tissue-specific rescue experiments of daf-2 null mutants. For each assay, $n \geq 9$. Tissue-specific promoters used in this experiment were the unc-54 promoter (body wall muscle), unc-14 promoter (all neurons) and ges-1 promoter (intestine). ges-1p::daf-2cDNA and unc-14p::daf-2cDNA were co-injected to allow coexpression in both the intestine and neurons. Abnormalities in $25^{\circ} \mathrm{C}$-cultivated daf- 2 animals were rescued by daf- $2 \mathrm{cDNA}$ co-expressed in both the intestine and neurons. For each assay, $n \geq 9$. (c) Cold tolerance in the cold receptor TRP channel and downstream signalling mutant ${ }^{33}$. PKC- 2 is a downstream molecule of cold receptor/TRPA-1 that functions in the intestine. pkc- 2 and trpa- 1 mutants did not show abnormal defects in cold tolerance. The trpa-1 mutation did not affect cold tolerance in the daf-2; trpa-1 double mutant. daf-2; trpa-1, wild type; XuEx601 and daf-2(e1370); XuEx601 strains were kindly provided by $\mathrm{Dr} \mathrm{Xu}^{33}$. Overexpression of TRPA-1 also did not affect cold tolerance in both the wild type and daf-2(e1370) mutant. For each assay, $n \geq 9$. Animals with the daf-2(e1370) mutation were cultivated at $15^{\circ} \mathrm{C}$ from egg to L4 larvae, and after that, animals were cultivated at 20 or $25^{\circ} \mathrm{C}$ overnight from $\mathrm{L} 4$ to adult because of the daf-c phenotype $(\mathbf{b}, \mathbf{c})$. Error bars indicate standard error of the mean. Analysis of variance followed by Dunnet post-hoc test was used for multiple comparisons. ${ }^{\star \star} P<0.01$.

kinase, and $h s p-16.2, h s p-16.41$ and $h s p-16.48 /$ heat-shock proteins, which are involved in the stress response. Phenotypic analysis of cold tolerance of these mutants showed that these mutants had a phenotype similar to wild-type animals
(Supplementary Fig. 5d), suggesting that these molecules are not necessary for cold tolerance.

Since the insulin-signalling pathway is involved in dauer larva formation, we tested other signalling molecules that are 
important for dauer larva formation, such as molecular components of transforming growth factor-beta (TGF- $\beta$ ) and steroid hormonal signalling (Fig. 6a) ${ }^{31}$. However, we did not observe strong defects in temperature experience-dependent cold tolerance in these mutants (Fig. 6a). These genetic experiments suggest that the insulin-signalling pathway is essential for cold tolerance, but that TGF- $\beta$ and steroid hormone signalling are not essential.

In many organisms, including the nematode, the percentage of different fatty acids in the body is important for the formation of cold tolerance ${ }^{1}$. A previous report by Murray et al. ${ }^{1}$ demonstrated that the percentage of fatty acids changed depending on the cultivation temperature, which was important for cold tolerance. In addition, Savory et al. ${ }^{2}$ showed that FOXO-type transcription factor DAF-16, which is involved in insulin signalling, is important for delta-9 desaturase gene expression, which is important for survival at low temperatures. We therefore measured the fatty acid composition of total lipids in daf-2/ insulin receptor mutants. We found that the fatty acid composition of total lipids was different between wild type and daf-2 mutants (Supplementary Fig. 6a,b). These results are consistent with previous reports that DAF-16/FOXO regulates genes involved in lipid production.

Insulin is a secretory molecule, and the insulin receptor DAF-2 is expressed in many tissues, such as neurons, muscles and intestine $^{32}$. To investigate tissues where DAF-2 functions in temperature experience-dependent cold tolerance, we tested the cold tolerance of $d a f-2$ animals expressing $d a f-2 c D N A$ in neurons, intestine or muscles. The tissue-specific rescue experiments revealed that the DAF-2/insulin receptor functions in both intestine and neurons (Fig. 6b, daf-2(e1370);Ex[unc-14p::daf-2, ges-1p::daf-2] (neuron and intestine)). These results suggest that the insulin-signalling pathway in intestine and neurons is essential for temperature experience-dependent cold tolerance of animals.

A recent study has shown that worm intestine itself is highly cold sensitive, and that this tissue plays a central role in ageing and the stress response, in which the cold receptor transient receptor potential (TRP) channel encoded by trpa-1 is essential ${ }^{33}$. We therefore tested the function of trpa-1 and its downstream molecule $p k c-2$ encoding protein kinase $\mathrm{C}$ in cold tolerance. Lossof-function mutants of trpa-1 and $p k c-2$ showed normal phenotypes when compared with wild type (Fig. 6c). Also, overexpression of the trpa-1 gene in wild-type intestine did not result in an abnormal phenotype (Fig. 6c (wild type; XuEx601)). Besides, overexpression of the trpa-1 gene in the daf-2/insulin receptor mutant did not suppress abnormalities in the daf-2 single mutants (Fig. 6c). These results indicate that TRPA-1 signalling in the intestine is independent of cold tolerance signalling.

To determine a downstream insulin-signalling pathway for temperature-dependent cold tolerance, we used previous DNA microarray analysis results measuring temperature changedependent gene expression ${ }^{34}$. We found that mutants of some genes, such as endonuclease (M60.2) and cysteine protease (cpr-1), showed abnormal cultivation-dependent cold tolerance (Fig. 7a; Supplementary Fig. 5a). Expression levels of these genes were significantly changed in daf-2/insulin receptor mutants (Fig. 7b; Supplementary Fig. 5b), indicating that expression of these genes is directly or indirectly regulated downstream of insulin signalling for temperature experience-dependent cold tolerance.

Because cold tolerance can be overwritten within 2-3h after the cultivation temperature is altered (Fig. 1f,g; Supplementary Fig. 1d,e), we examined calcium measurements in the ASJ neurons during longer times by extending the calcium imaging assays to measure points at $30 \mathrm{~min}$ to $5 \mathrm{~h}$ (Fig. 3e). We found that the calcium concentration was at its maximum at $30 \mathrm{~min}$ after the temperature changed from $17-23^{\circ} \mathrm{C}$, and was strongly decreased at $1 \mathrm{~h}$. The results of calcium imaging of ASJ neurons over longer time periods after warming (Fig. 3e) showed a prolonged response of ASJ neurons to a step in temperature; it is a sustained response to a higher temperature over $30 \mathrm{~min}$, and it is not a short-term transient response to a changing temperature shown in Fig. 3b. This would be expected in a process having long-term effects on cold tolerance. Physiological calcium imaging analysis in this study suggests that ASJ neurons continue to respond to temperature for at least $30 \mathrm{~min}$ (Fig. 3e). Since the cold tolerance phenotype can be replaced within $2-3 \mathrm{~h}$ after changing the cultivation temperature (Fig. 1f,g; Supplementary Fig. 1d,e), ASJ-dependent insulin secretion could continue for $30 \mathrm{~min}$ to $1 \mathrm{~h}$. After that, downstream events of insulin signalling, such as gene expression and changing cell metabolism in the intestine and neurons, may determine cold tolerance within $2-3 \mathrm{~h}$.

\section{Discussion}

Exploring the mechanisms for temperature habituation of animals is an important challenge in life sciences. The results in this study demonstrated that experience-dependent cold tolerance is regulated by a single sensory neuron, ASJ, known as light and pheromone-sensing neuron. ASJ neurons release insulin, which is received by the intestine and other neurons in C. elegans (Fig. 7c).

Our genetic and physiological analysis suggested that ASJ sensory neurons secrete insulin molecules that result in decreasing cold tolerance in wild-type animals. Thus, ASJ-dependent insulin signalling acts as a negative regulator of cold tolerance. In contrast, our genetic model described a positive regulator, the DAF-16/FOXO-type transcription factor. Because daf-16 single mutants only showed a partial decrement of cold tolerance after cultivation at $18^{\circ} \mathrm{C}$ (Supplementary Fig. 4b), we hypothesize that there is additional positive signalling in cold tolerance. As previously reported, DAF-16 regulates the gene expression of the delta-9 desaturase gene, which is important for cold tolerance in many animals, including worms, and impairment of the delta- 9 desaturase gene decreases cold tolerance in worms ${ }^{2}$. Based on these data, we propose two plausible models. In the first model, an unidentified temperature-sensing system in the nervous system and/or other tissues controls positive signalling for cold tolerance, although mutant animals with an impaired nervous system have not shown an abnormal decrement of cold tolerance. Alternatively, we can propose another model, where DAF-16 and an unidentified transcription factor could be activated under default conditions without temperature stimuli. This model is consistent with a previous result, where translocation of DAF-16/ FOXO between the nucleus and cytoplasm is not observed following cold stimuli ${ }^{2}$, but is observed at ambient temperatures. In either model, ASJ-dependent temperature signalling acts as a gain-controller of cold tolerance through negative regulation of positive signalling for cold tolerance. It is also likely that the cold tolerance is accomplished by more complicated mechanisms, although we describe here a simpler plausible genetic and physiological model (Fig. 7c).

Molecular physiological systems are mainly conserved from humans to $C$. elegans, and the systems found in this study can therefore provide a useful model for studying temperature habituation in other animals. Our current work helps explain a complex mechanism for temperature habituation, from stimulus sensing through the neuronal and intestinal reactions that produce temperature tolerance. 
a

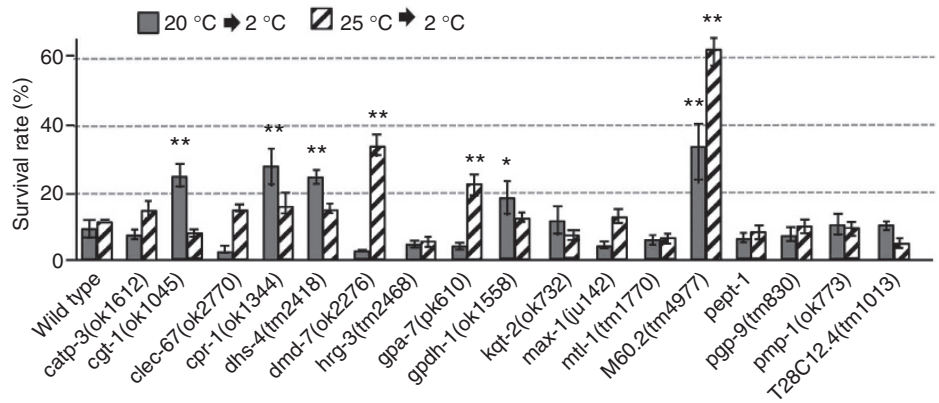

b
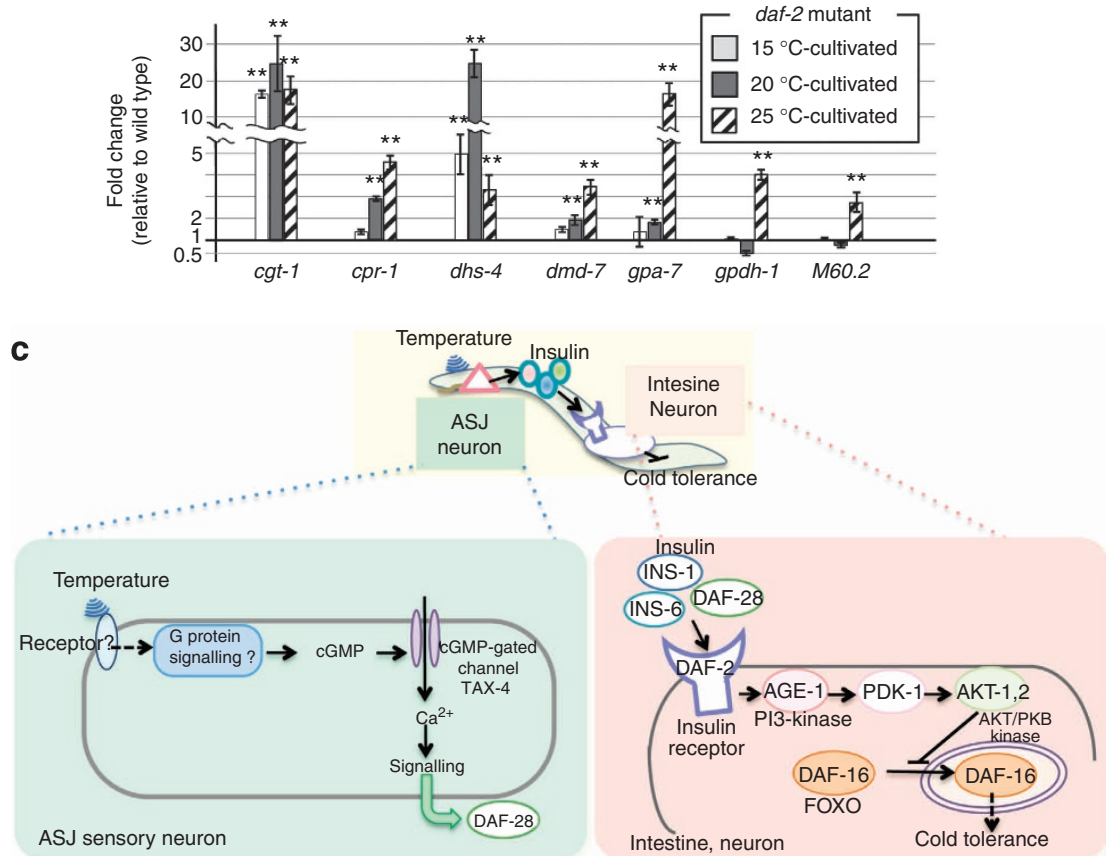

Figure 7 | Downstream molecules of insulin signalling in cold tolerance. (a) Cold tolerance of mutant animals with impaired genes identified from previous DNA microarray analysis were used to measure temperature change-dependent gene expression ${ }^{34}$. The gene and encoding protein of the mutants that showed abnormal cold tolerance (with asterisks) are listed in the table in Supplementary Fig. 5a. For each assay, $n \geq 6$. Asterisks indicate statistical significance between the wild type and mutant. (b) Results of quantitative PCR of each gene in the daf-2(e1370) mutant. Each bar represents the relative value of wild type cultivated at each temperature $(n=3)$. Error bars indicate standard error of the mean. Analysis of variance followed by Dunnet post-hoc test was used for multiple comparisons. ${ }^{\star} P<0.05 ;{ }^{\star \star} P<0.01$. (c) A molecular and cellular model for temperature experience-inducing cold tolerance. Temperature is detected by the ASJ neuron, in which the trimeric G protein-coupled temperature signal controls insulin secretion. Insulin is received by the intestine and neuron, where insulin signalling regulates gene expression for cold tolerance. We describe here a simple plausible model.

\section{Methods}

Statistical analysis. All error bars in the figures, including those in the Supplementary Information, indicate standard error of mean. All statistical analyses in the figures, including those in the Supplementary Information, were performed by one-way analysis of variance for multiple comparisons, which were followed by Dunnet post-hoc tests. All single asterisk ${ }^{*}$ ) and double asterisk $(* *)$ in the figures indicate $P<0.05$ and $P<0.01$, respectively. $P$ indicates probability.

Molecular biology. trx-1p::tax-4 cDNA(pTOM4), str-3p::tax-4 cDNA(pTOM3) and ceh-36p::tax-4 cDNA(pTOM10) used in Fig. 2e include tax-4 $c D N A$ that was PCR amplified from pDEST-tax-4cDNA (a gift from Dr Iino) ${ }^{35}$ and the $3^{\prime}$ untranslated region of unc-54. In addition, pTOM4 includes the ASJ-specific trx-1 promoter $(1.0 \mathrm{~kb})^{36}$, which was from pQZ37 trx-1p::ICE (a gift from Dr Alcedo). pTOM3 includes the ASI-specific str-3 promoter $(3.1 \mathrm{~kb})$ from pQZ36 (str-3p::GFP, a gift from Dr Alcedo). pTOM10 includes the AWC-specific ceh-36 promoter (368 bp) from pAK203.

daf-28 cDNA inserted into pUC57 was purchased from GenScript, a DNA synthesizing outsource service company. The trx-1 promoter of trx-1p::daf-28 cDNA (pTOM6), the str-3 promoter of str-3p::daf-28 cDNA(pTOM7) and the ceh36 promoter of $c e h-36 p::$ daf-28 cDNA (pTOM8) used the same fragment as mentioned above.
To construct DAF-28 fused with fluorescent protein (trx-1p::daf-28:: dsRedm (pOTA11)), we deleted the stop codon of daf-28 cDNA from pTOM6 by sitedirected mutagenesis, and then the DsRed monomer DNA was inserted between the daf-28 cDNA and the $3^{\prime}$-untranslated region. trx-1p::snb-1::VENUS (pOTA5) was replaced by the trx-1 promoter from the promoter region of pTAN93 ( $g l r-$ $3 p:: s n b-1::$ VENUS) ${ }^{37}$

$\operatorname{trx}-1 p:: y c 3.60$ was constructed from $1.0 \mathrm{~kb}$ trx-1p and the $y c 3.60$ gene derived from pSAS309 $(g c y-8 p:: y c 3.60)^{17,38}$.

daf-2 cDNA (Pdpy30-daf-2cDNA) was provided by Dr Iino and Dr Tomioka. For the construction of $u n c-14 p::$ daf-2cDNA or ges-1p::daf-2cDNA, the PCRamplified fragment of daf-2 $c D N A$ was inserted into each plasmid including a 1.5$\mathrm{kb}$ unc-14 promoter (from plasmid $\mathrm{pTTu} 14 \mathrm{p})^{39}$ or a $3.3 \mathrm{~kb}$ ges-1 promoter (from plasmid pKDK66) ${ }^{17}$. PCR-amplified fragments were verified by sequencing.

Temperature experience-inducing cold tolerance assay. Uncrowded and wellfed animals were used for the cold tolerance assay. Two adult animals were placed on a $6-\mathrm{cm}$ plate containing $14 \mathrm{ml}$ of nematode growth medium (NGM) with $2 \%$ (w/v) agar, on which Escherichia coli OP50 was seeded; the adult animals were transferred to the outside of plate after 8-12 $\mathrm{h}$; the progeny were cultured for about $144-150 \mathrm{~h}$ at $15^{\circ} \mathrm{C}, 85-90 \mathrm{~h}$ at $20^{\circ} \mathrm{C}$ or $60-65 \mathrm{~h}$ at $25^{\circ} \mathrm{C}$. Approximately $70-150$ animals were placed on a plate. The plates containing fully matured but not old adult animals were transferred to $2^{\circ} \mathrm{C}$ (Figs 2-7; Supplementary Figs 3-5) or to a 
designated cold temperature (Fig. 1; Supplementary Fig. 1) in a refrigerated cabinet (MIR-553, Sanyo, Japan). Temperature was monitored by both a digital thermometer and a mercury thermometer. After $48 \mathrm{~h}$ (Figs 2-7; Supplementary Figs 3-5) or a designated time (Fig. 1; Supplementary Fig. 1), the plates were transferred to room temperature $\left(22-24^{\circ} \mathrm{C}\right)$, and the living or dead animals on the plate were counted.

In vivo calcium imaging. In vivo calcium imaging was performed essentially according to previous reports ${ }^{17,38}$. Well-fed animals expressing yellow cameleon 3.60 driven by the trx-1 promoter, trx-1p::yc3.60 (pTOM13), were used for calcium imaging. Animals were glued onto a $2 \%(\mathrm{w} / \mathrm{v})$ agar pad on glass, immersed in M9 buffer and covered by a cover glass. For long time calcium imaging (Fig. 3e), animals were immobilized by $0.1-\mu \mathrm{m}$ diameter polystyrene microspheres (Polysciences $00876-15,2.5-5 \% \mathrm{w} / \mathrm{v}$ suspension) on $10 \%(\mathrm{w} / \mathrm{v})$ agar pads on glass, and covered by a cover glass. After long time calcium imaging, animals were checked to still be alive. Sample preparation was completed within $3 \mathrm{~min}$. The sample was then placed onto a Peltier-based thermocontroller (Tokai Hit, Japan) on the stage of an Olympus IX81 at the initial imaging temperature for 2 min, and fluorescence was introduced into a Dual-View optics system (Molecular Devices, USA). Fluorescence images of donor and acceptor fluorescent protein in yellow cameleon were simultaneously captured using an EM-CCD camera EVOLVE512 (Photometrics, USA). Images were taken with a 100 -ms exposure time with $1 \times 1$ binning. The temperature on the agar pad was monitored by a thermometer system, MATS-5500RA-KY (Tokai Hit). For each imaging experiment, fluorescence intensities were measured using the MetaMorph image analysis system (Molecular Device). Relative changes in intracellular calcium concentration were measured as the change in the acceptor/donor fluorescence ratio of yellow cameleon protein (ratio change). All band pass filters for experiments using yellow cameleon were according to previous reports ${ }^{17}$.

Germline transformation. Germline transformations were essentially performed as described previously ${ }^{40}$. Germline transformations were performed with coinjection mixes consisting of experimental DNA at various concentrations (5-

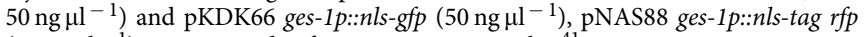
$\left(50 \mathrm{ng} \mu \mathrm{l}^{-1}\right)$, or pRF4 rol-6gf as a transgenic marker ${ }^{41}$.

Fatty acid composition. Lipids were extracted from synchronized cultures of young adults and transmethylated as described previously ${ }^{1}$. Fatty acid methyl esters were analyzed by gas-liquid chromatography and identified by comparing peak retention times with authentic standards. Fatty acid compositions are presented on a percentage weight basis.

Quantitative PCR analysis. Wild-type animals and daf-2 mutants were individually synchronized at $15^{\circ} \mathrm{C}$. Animals were transferred to 20 or $25^{\circ} \mathrm{C}$, after cul tivation at $15^{\circ} \mathrm{C}$ for 5 days until they passed the L1-L3 larval stage, because daf-2 mutants show a constitutive dauer larva formation phenotype at $25^{\circ} \mathrm{C}$. Messenger RNA was isolated using the RNeasy kit (Qiagen). The isolated messenger RNA (100 ng) was reverse-transcribed to cDNA using the iScript Advanced cDNA Synthesis kit for RT-PCR (Bio-Rad). Quantitative PCR was performed using primers specific to the genes, Sso Fast EvaGreen Supermix (Bio-Rad) and a DNA Engine Peltier Thermal Cycler-CFX96 (Bio-Rad). Triplicate samples of each dilution were used for quantitative PCR. The average expression of each gene was normalized to that of the house-keeping gene $\operatorname{lmn}-1$ as a reference ${ }^{34}$. The following sets of primers were used for the detection of $c g t-1 ; 5^{\prime}$-GCGATTTTTAT GAGACCCGATG- $3^{\prime}$ and $5^{\prime}$-CGAACATACAACGCCGAGAA- ${ }^{\prime}$, cpr-1; $5^{\prime}$-AGCT GGATGCAAACCATACC- $3^{\prime}$ and $5^{\prime}$-GGAACAGCGTAGGCAGAGAC- $3^{\prime}$, dhs-4; $5^{\prime}$-CTTCGATGTTTGACGCCACT- $3^{\prime}$ and $5^{\prime}$-CGACCATTGCCTGAGCTTT- ${ }^{\prime}$, $d m d-7 ; 5^{\prime}$-AACGCGAACAGCTAAATGGA- $3^{\prime}$ and $5^{\prime}$-GCGTGCCCTTTCA GTACAAC- $3^{\prime}$, gpa-7; $5^{\prime}$-TCGACGCAGCAATGAATACC- $3^{\prime}$ and $5^{\prime}$-TGCCCTC CAACATCTATCACTC- $3^{\prime}$, gpdh-1; $5^{\prime}$-GGGTGACAACGGATTATGAGG-3' and $5^{\prime}$-CCGACGGAACTTGGGTAGAA- ${ }^{\prime}$, M60.2; $5^{\prime}$-AAGAAGAGCCCAGACCAC GA- $3^{\prime}$ and $5^{\prime}$-CATCCGAGGCAATGAAGTTGT- $3^{\prime}$.

Laser ablation experiments. Laser ablation experiments were performed essentially according to previous reports ${ }^{5,6}$. ASJ neurons were killed in anesthetized wild-type animals at the L2-3 stage using a Micropoint system laser microbeam (Photonic Instruments, USA). After laser operation, each animal that had been grown at $20^{\circ} \mathrm{C}$ to an adult stage on the Nematode growth media (NGM) plate with sufficient food, E. coli OP50, was tested for cold tolerance at $2{ }^{\circ} \mathrm{C}$ for $48 \mathrm{~h}$.

RNA interference. The C. elegans RNA interference (RNAi) library, which had originally been established by Dr Ahringer, was purchased from Source BioScience ${ }^{42}$ and used for all RNAi analyses in this study. The feeding RNAi protocol was performed as described ${ }^{43}$. The eri-1; lin-15B strain was ${ }^{44,45}$ used as a neuron-sensitized strain for RNAi experiments.
Confocal microscopy analysis. Preparation of samples was according to the following procedure: a $2 \%(\mathrm{w} / \mathrm{v})$ agarose gel on a micro slide glass was covered with $10 \mu \mathrm{l}$ of $100-\mathrm{mM} \mathrm{NaN}_{3}$ and then a few adult worms were placed on the gel. Finally, the gel was covered by glass. Fluorescent images were analyzed by confocal laser microscopy (FV1000-IX81 with GaAsP photomultiplier tubes, Olympus), using FV10-ASW software (Olympus).

\section{References}

1. Murray, P., Hayward, S. A., Govan, G. G., Gracey, A. Y. \& Cossins, A. R. An explicit test of the phospholipid saturation hypothesis of acquired cold tolerance in Caenorhabditis elegans. Proc. Natl Acad. Sci. USA 104, 5489-5494 (2007).

2. Savory, F. R., Sait, S. M. \& Hope, I. A. DAF-16 and Delta9 desaturase genes promote cold tolerance in long-lived Caenorhabditis elegans age-1 mutants. Plos One 6, e24550 (2011).

3. Hall, D. H. \& Hedgecock, E. M. Kinesin-related gene unc-104 is required for axonal transport of synaptic vesicles in C. elegans. Cell 65, 837-847 (1991).

4. Otsuka, A. J. et al. The C. elegans unc-104 gene encodes a putative kinesin heavy chain-like protein. Neuron 6, 113-122 (1991).

5. Mori, I. \& Ohshima, Y. Neural regulation of thermotaxis in Caenorhabditis elegans. Nature 376, 344-348 (1995).

6. Kuhara, A. et al. Temperature sensing by an olfactory neuron in a circuit controlling behavior of C. elegans. Science 320, 803-807 (2008).

7. Ohta, A. \& Kuhara, A. Molecular mechanism for trimeric G protein-coupled thermosensation and synaptic regulation in the temperature response circuit of Caenorhabditis elegans. Neurosci. Res. 76, 119-124 (2013).

8. Kuhara, A., Inada, H., Katsura, I. \& Mori, I. Negative regulation and gain control of sensory neurons by the C. elegans calcineurin TAX-6. Neuron 33, 751-763 (2002).

9. Kuhara, A. \& Mori, I. Molecular physiology of the neural circuit for calcineurin-dependent associative learning in Caenorhabditis elegans. J. Neurosci. 26, 9355-9364 (2006).

10. Haycraft, C. J., Schafer, J. C., Zhang, Q., Taulman, P. D. \& Yoder, B. K. Identification of CHE-13, a novel intraflagellar transport protein required for cilia formation. Exp. Cell. Res. 284, 251-263 (2003).

11. Perkins, L. A., Hedgecock, E. M., Thomson, J. N. \& Culotti, J. G. Mutant sensory cilia in the nematode Caenorhabditis elegans. Dev. Biol. 117, 456-487 (1986).

12. Collet, J., Spike, C. A., Lundquist, E. A., Shaw, J. E. \& Herman, R. K. Analysis of osm-6, a gene that affects sensory cilium structure and sensory neuron function in Caenorhabditis elegans. Genetics 148, 187-200 (1998).

13. Deane, J. A., Cole, D. G., Seeley, E. S., Diener, D. R. \& Rosenbaum, J. L. Localization of intraflagellar transport protein IFT52 identifies basal body transitional fibers as the docking site for IFT particles. Curr. Biol. 11, 1586-1590 (2001).

14. Komatsu, H., Mori, I., Rhee, J. S., Akaike, N. \& Ohshima, Y. Mutations in a cyclic nucleotide-gated channel lead to abnormal thermosensation and chemosensation in C. elegans. Neuron 17, 707-718 (1996).

15. Liu, J. et al. C. elegans phototransduction requires a $\mathrm{G}$ protein-dependent cGMP pathway and a taste receptor homolog. Nat. Neurosci. 13, 715-722 (2010).

16. Miyawaki, A. et al. Fluorescent indicators for $\mathrm{Ca} 2+$ based on green fluorescent proteins and calmodulin. Nature 388, 882-887 (1997).

17. Kuhara, A., Ohnishi, N., Shimowada, T. \& Mori, I. Neural coding in a single sensory neuron controlling opposite seeking behaviours in Caenorhabditis elegans. Nat. Commun. 2, 355 (2011).

18. Larsen, P. L. Aging and resistance to oxidative damage in Caenorhabditis elegans. Proc. Natl Acad. Sci. USA 90, 8905-8909 (1993).

19. Vanfleteren, J. R. Oxidative stress and ageing in Caenorhabditis elegans. Biochem. J. 292 Pt 2, 605-608 (1993).

20. Murakami, S. \& Johnson, T. E. A genetic pathway conferring life extension and resistance to UV stress in Caenorhabditis elegans. Genetics 143, 1207-1218 (1996).

21. Barsyte, D., Lovejoy, D. A. \& Lithgow, G. J. Longevity and heavy metal resistance in daf-2 and age-1 long-lived mutants of Caenorhabditis elegans. FASEB J. 15, 627-634 (2001).

22. Garsin, D. A. et al. Long-lived C. elegans daf-2 mutants are resistant to bacterial pathogens. Science 300, 1921 (2003).

23. Lamitina, S. T. \& Strange, K. Transcriptional targets of DAF-16 insulin signaling pathway protect $C$. elegans from extreme hypertonic stress. American journal of physiology. Cell Physiol. 288, C467-C474 (2005).

24. Cornils, A., Gloeck, M., Chen, Z., Zhang, Y. \& Alcedo, J. Specific insulin-like peptides encode sensory information to regulate distinct developmental processes. Development 138, 1183-1193 (2011).

25. Li, W., Kennedy, S. G. \& Ruvkun, G. daf-28 encodes a C. elegans insulin superfamily member that is regulated by environmental cues and acts in the DAF-2 signaling pathway. Genes Dev. 17, 844-858 (2003).

26. Kodama, E. et al. Insulin-like signaling and the neural circuit for integrative behavior in C. elegans. Genes Dev. 20, 2955-2960 (2006). 
27. Ishihara, T. et al. HEN-1, a secretory protein with an LDL receptor motif, regulates sensory integration and learning in Caenorhabditis elegans. Cell 109, 639-649 (2002).

28. Kimura, K. D., Tissenbaum, H. A., Liu, Y. \& Ruvkun, G. daf-2, an insulin receptor-like gene that regulates longevity and diapause in Caenorhabditis elegans. Science 277, 942-946 (1997).

29. Malone, E. A., Inoue, T. \& Thomas, J. H. Genetic analysis of the roles of daf-28 and age-1 in regulating Caenorhabditis elegans dauer formation. Genetics 143, 1193-1205 (1996).

30. Pierce, S. B. et al. Regulation of DAF-2 receptor signaling by human insulin and ins-1, a member of the unusually large and diverse C. elegans insulin gene family. Genes Dev. 15, 672-686 (2001).

31. Fielenbach, N. \& Antebi, A. C. elegans dauer formation and the molecular basis of plasticity. Genes Dev. 22, 2149-2165 (2008).

32. Wolkow, C. A., Kimura, K. D., Lee, M. S. \& Ruvkun, G. Regulation of C. elegans life-span by insulinlike signaling in the nervous system. Science 290, 147-150 (2000).

33. Xiao, R. et al. A genetic program promotes C. elegans longevity at cold temperatures via a thermosensitive TRP channel. Cell 152, 806-817 (2013).

34. Sugi, T., Nishida, Y. \& Mori, I. Regulation of behavioral plasticity by systemic temperature signaling in Caenorhabditis elegans. Nat. Neurosci. 14, 984-992 (2011).

35. Hirotsu, T., Saeki, S., Yamamoto, M. \& Iino, Y. The Ras-MAPK pathway is important for olfaction in Caenorhabditis elegans. Nature 404, 289-293 (2000).

36. Miranda-Vizuete, A. et al. Lifespan decrease in a Caenorhabditis elegans mutant lacking TRX-1, a thioredoxin expressed in ASJ sensory neurons. FEBS Lett. 580, 484-490 (2006).

37. Tanizawa, Y. et al. Inositol monophosphatase regulates localization of synaptic components and behavior in the mature nervous system of C. elegans. Genes Dev. 20, 3296-3310 (2006).

38. Ohnishi, N., Kuhara, A., Nakamura, F., Okochi, Y. \& Mori, I. Bidirectional regulation of thermotaxis by glutamate transmissions in Caenorhabditis elegans. EMBO J. 30, 1376-1388 (2011).

39. Ogura, K., Shirakawa, M., Barnes, T. M., Hekimi, S. \& Ohshima, Y. The UNC-14 protein required for axonal elongation and guidance in Caenorhabditis elegans interacts with the serine/threonine kinase UNC-51. Genes Dev. 11, 1801-1811 (1997).

40. Mello, C. C., Kramer, J. M., Stinchcomb, D. \& Ambros, V. Efficient gene transfer in C.elegans: extrachromosomal maintenance and integration of transforming sequences. EMBO J. 10, 3959-3970 (1991).

41. Mello, C. C., Kramer, J. M., Stinchcomb, D. \& Ambros, V. Efficient gene transfer in C.elegans: extrachromosomal maintenance and integration of transforming sequences. EMBO J. 10, 3959-3970 (1991).

42. Fraser, A. G. et al. Functional genomic analysis of C. elegans chromosome I by systematic RNA interference. Nature 408, 325-330 (2000).

43. Kamath, R. S., Martinez-Campos, M., Zipperlen, P., Fraser, A. G. \& Ahringer, J. Effectiveness of specific RNA-mediated interference through ingested doublestranded RNA in Caenorhabditis elegans. Genome Biol. 2, RESEARCH0002 (2001).

44. Timmons, L. \& Fire, A. Specific interference by ingested dsRNA. Nature 395, 854 (1998).
45. Kennedy, S., Wang, D. \& Ruvkun, G. A conserved siRNA-degrading RNase negatively regulates RNA interference in C. elegans. Nature 427, 645-649 (2004).

46. Henderson, S. T. \& Johnson, T. E. daf-16 integrates developmental and environmental inputs to mediate aging in the nematode Caenorhabditis elegans. Curr. Biol. 11, 1975-1980 (2001).

\section{Acknowledgements}

We thank I. Mori, X.Z.S. Xu, J. Alcedo, C.I. Bargmann, Y. Iino, S. Tomioka, T. Takasaki, H. Sakamoto, I. Hope and S. Mitani for sharing DNA constructs and strains; K. Takeda for technical advice; the National Bioresource Project (Japan) and the Caenorhabditis Genetic Center for strains; N. Inoue, T. Inoue, Y. Kobayashi, Y. Kinoshita, M. Endo, K. Kanai and N. Kuwahara for supporting experiments; the members of the Kuhara laboratory for comments on this manuscript and stimulating discussion; Anonymous reviewers for invaluable comments on the manuscript. A.K. was supported by the Toray Science Foundation, the Sumitomo Foundation, the Astellas Foundation, the Senri Life Science Foundation, the Simazu Foundation, the Novartis Foundation, the Mitsubishi Foundation, the Naito Foundation, the Casio Foundation, the Research Foundation for Opto-Science and Technology, the Asahi Glass Foundation, the Hirao Taro Foundation of Konan University, JSPS KAKENHI, grant-in-aid for Young Scientists (A) and grantin-aid for the Challenging Exploratory Research, and Grant-in-Aid for Scientific Research on Innovative Areas from the Ministry of Education, Culture, Sports, Science and Technology (MEXT) of Japan. A.O. was supported by the Sasagawa Science Foundation, the Naito Foundation, the Narishige Zoological Science Award and grantin-aid for JSPS Fellows (KAKENHI), Japan.

\section{Author contributions}

A.O., T.U. and S.S. performed the experiments; A.K. developed the experimental systems; A.O., T.U. and A.K. designed and interpreted the experiments, and wrote the paper.

\section{Additional information}

Supplementary Information accompanies this paper at http://www.nature.com/ naturecommunications

Competing financial interests: The authors declare no competing financial interests.

Reprints and permission information is available online at http://npg.nature.com/ reprintsandpermissions/

How to cite this article: Ohta, A. et al. Light and pheromone-sensing neurons regulates cold habituation through insulin signalling in Caenorhabditis elegans. Nat. Commun. 5:4412 doi: 10.1038/ncomms5412 (2014).

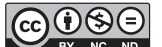

This work is licensed under a Creative Commons AttributionNonCommercial-NoDerivs 4.0 International License. The images or other third party material in this article are included in the article's Creative Commons license, unless indicated otherwise in the credit line; if the material is not included under the Creative Commons license, users will need to obtain permission from the license holder to reproduce the material. To view a copy of this license, visit http:// creativecommons.org/licenses/by-nc-nd/4.0/ 